\title{
FUNDO ROTATIVO SOLIDÁRIO DO QUILOMBO MARANHENSE PIQUI DA RAMPA: INSTRUMENTO DE FINANÇA SOLIDÁRIA E AUTOGESTÃO
}

\section{PIQUI DA RAMPA QUILOMBOLA COMMUNITY SOLIDARY REVOLVING FUND IN MARANHÃO: INSTRUMENT OF SOLIDARY FINANCE AND SELF-MANAGEMENT}

\author{
José Edilson do Nascimento ${ }^{1}$ \\ Jaíra Maria Alcobaça Gomes ${ }^{2}$ \\ Elisângela Guimarães Moura Fé
}

\begin{abstract}
Resumo
Este artigo analisa o Fundo Rotativo da Comunidade Quilombola Piqui da Rampa, o qual tem se constituído como importante instrumento de finança solidária. O Piqui da Rampa está localizado no município de Vargem Grande, Estado do Maranhão, Brasil. O referido fundo foi constituído por inciativa da Associação do Piqui da Rampa com a finalidade de conceder doações ou empréstimos para moradores que estejam com dificuldades para solucionar problemas relacionados com questões de saúde, viagens, funerais etc. A análise está baseada em fontes de informações primárias, obtidas a partir de entrevistas junto a membros fundadores e dirigentes da associação e da aplicação de formulários junto aos chefes das famílias da comunidade. Os resultados apontam que o Fundo Rotativo do Piqui da Rampa é mantido através dos excedentes gerados pela comercialização dos produtos agrícolas, dos lucros obtidos a partir do tradicional festejo da farinha e das diárias de trabalho dispensadas em prol da associação. As características deste fundo convergem para as definições e classificações existentes, contudo o mesmo precisa avançar em relação à formalização, organização administrativa, registros e controle das atividades. As ações solidárias desenvolvidas pelo Fundo Rotativo do Piqui da Rampa desempenham uma função que ultrapassa a simples questão da doação. A sua importância está relacionada com valores e princípios que são construídos ou realçados como a solidariedade e a reciprocidade.
\end{abstract}

Palavras-chaves: Organização Associativa. Solidariedade. Reciprocidade.

\footnotetext{
${ }^{1}$ Doutor em Desenvolvimento e Meio Ambiente pela Universidade Federal do Piauí (PRODEMA/UFPI). Professor de Geografia do Instituto Federal do Maranhão (IFMA), Campus São Luís - Monte Castelo. Bolsista PROQUALIS/IFMA, São Luís - MA, Brasil. E-mail: edilson@ifma.edu.br

${ }^{2}$ Doutora em Economia Aplicada pela ESALQ/USP. Professora do Departamento de Economia e dos Programas de PósGraduação em Desenvolvimento e Meio Ambiente e Políticas Públicas da Universidade Federal do Piauí, Teresina - PI, Brasil. E-mail: jaira@ufpi.edu.br

${ }^{3}$ Doutora em Desenvolvimento e Meio Ambiente pela Universidade Federal do Piauí (PRODEMA/UFPI). Professora de Geografia do Instituto Federal do Maranhão (IFMA), Buriticupu - MA, Brasil. E-mail: guimaraeselisangela@yahoo.com.br
} 


\begin{abstract}
The aim of the current article is to assess the Piqui da Rampa Quilombola Community Solidarity Revolving Fund, which has been an important solidarity finance instrument. Piqui da Rampa is located in Vargem Grande City, Maranhão State, Brazil. The fund was set as an initiative by Piqui da Rampa Association to grant donations or loans to residents who struggling to solve problems related to health, travel, funerals, among others. The assessment was based on primary information sources collected through interviews with the association's founding members and leaders and thought the application of forms to the heads of households in the community. Based on the results, Piqui da Rampa Solidarity Revolving Fund is afforded by surpluses generated by agricultural products' trading and by profits from the traditional flour festival and by days worked on behalf of the association. Fund features converge to the existing definitions and classifications regarding Solidary Revolving Fund; however, it must advance to its formalization, administrative organization, record and control of activities. The role played by solidarity actions developed by Piqui da Rampa Solidarity Revolving Fund goes beyond simply asking for donation, since its importance is related to values and principles such as solidarity and reciprocity.
\end{abstract}

Keywords: Associative Organization. Solidarity. Reciprocity.

\title{
Introdução
}

O território brasileiro é marcado por enormes desigualdades econômicas e sociais. Para muitas famílias, essas desigualdades representam dificuldades, inclusive, para obterem o mínimo necessário que lhes garanta a própria sobrevivência. Diante de tal situação, surgem as estratégias da Economia Solidária, pautadas no trabalho coletivo, na reciprocidade e na solidariedade com o propósito de amenizar tais dificuldades, mediante a geração de trabalho e renda.

Para Singer (2002), a Economia Solidária constitui um modo de produção, cujos princípios básicos são a propriedade coletiva ou associada do capital e o direito à liberdade individual. A aplicação desses princípios une todos os que produzem numa única classe de trabalhadores, tornando-os possuidores do capital de forma igual em cada cooperativa ou sociedade econômica. Ela é ou poderá ser mais do que uma mera resposta à incapacidade do capitalismo de integrar em sua economia todos os membros da sociedade desejosos e necessitados de trabalhar.

Os Fundos Rotativos (Comunitários) Solidários, os Bancos Comunitários, os Clubes de Trocas, as Entidades de Microcrédito e as Cooperativas de Crédito são exemplos de iniciativas que constituem as Finanças da Economia Solidária. Embora se reconheça a importância de todas elas, neste artigo faz-se a opção de tratar, especificamente, dos Fundos Rotativos Solidários (FRSs).

Os FRSs são caracterizados como instrumentos de finanças solidárias direcionados às comunidades que, a partir da autogestão, criam uma poupança voluntária, onde parte dos recursos é aplicada na solução de problemas que afetam os próprios membros da comunidade. As relações democráticas, participativas e solidárias compõem as bases destes fundos (SANTOS FILHO et al., 2012).

Nessa perspectiva, destaca-se o caso do FRS da Comunidade Quilombola Piqui da Rampa, localizada na zona rural do município maranhense de Vargem Grande. Este fundo foi constituído a partir da atuação da Associação Comunitária do Povoado Piqui. Assim, desde a sua constituição no início dos anos 2000, as famílias da comunidade passaram a recorrer ao referido fundo para terem os seus problemas solucionados ou amenizados.

Portanto, este artigo tem o objetivo de analisar o FRS do Piqui da Rampa, o qual tem se constituído como importante instrumento de finança solidária. Especificamente, busca-se caracterizar a organização associativa do Piqui da Rampa.

Diante disso, compreende-se a relevância de se buscar a compreensão da organização, gestão e dinâmica do referido fundo como estratégia de desenvolvimento da Economia Solidária em comunidades rurais.

Além dessa introdução, o artigo apresenta cinco outras seções. Na segunda seção, faz-se uma discussão conceitual e histórica sobre a Economia Solidária. Na terceira, discute-se a importância 
social dos FRSs. Na quarta seção correspondente à metodologia, apresentam-se a delimitação da área de estudo, as fontes das informações, os instrumentos de coleta e de análises. Na quinta seção, realizam-se a caracterização da organização associativa da comunidade e as ações solidárias realizadas a partir do FRS do Piqui da Rampa.

\section{Uma discussão conceitual e histórica sobre a Economia Solidária}

A Economia Solidária surge após o capitalismo industrial como reação ao espantoso empobrecimento dos artesãos provocado pela difusão das máquinas e da organização fabril da produção. A partir do pensamento e influência de teóricos como Robert Owen, os trabalhadores no século XIX passaram a se organizar através de cooperativas como uma forma de resistência contra o avanço avassalador do capitalismo industrial. Por meio da constituição de uma cooperativa de consumo em 1844, os pioneiros de Rochdale estabeleceram as bases dos princípios cooperativistas, isto é, a livre adesão, o controle democrático, a neutralidade política e religiosa, a venda à vista e em dinheiro, a devolução dos excedentes, o interesse limitado sobre o capital e a educação contínua (SINGER, 2002).

De acordo com Gadotti (2009), o sistema de gestão da Economia Solidária é uma das características que a diferencia da Economia Capitalista. Assim, enquanto a gestão capitalista está voltada para o acúmulo do capital e para o lucro, a solidária está direcionada para a melhoria da qualidade de vida dos associados. Destaca-se que apesar da proximidade dos fundamentos da Economia Solidária com os princípios socialistas, esta foi implantada e se desenvolveu em muitas sociedades capitalistas.

Singer (2003, p. 116) distingue as organizações de produtores, consumidores e poupadores da Economia Solidária por duas especificidades: "a) estimulam a solidariedade entre os membros mediante a prática da autogestão e (b) praticam a solidariedade para com a população trabalhadora em geral, com ênfase na ajuda aos mais desfavorecidos".

Wellen (2008) faz uma ressalva aos defensores da solidariedade apresentada como uma das qualidades dos empreendimentos solidários, pois ela serve mais como valor de troca agregado à publicidade do que representa uma prática concreta. Desse modo, a solidariedade passa a ser uma mercadoria tal como qualquer outra, usada para agregar valor econômico à empresa.

Embora as práticas econômicas solidárias sejam alvo de críticas, já são praticadas por diversos povos e em diferentes países. Nesse sentido, Santiago (2014) destaca as iniciativas e experiências solidárias ocorridas na América Latina que contribuíram para consolidá-la e que se dão no âmbito da autogestão. Sobressaem-se as seguintes iniciativas: criação da lei geral da Economia Solidária na Colômbia; a Rede Nacional de Comercialización Comunitaria (RENACC) da Bolívia; no Equador a experiência de Maquita Cushinchic (MCCH); na Argentina o Espacio Nacional de Economia Social y Solidária (NESS); e o caso da Venezuela através da Central de Cooperativas de Comercio y Servicio Solidario (CECOCESOLA).

No Brasil, as práticas sociais e econômicas pautadas na solidariedade e na reciprocidade sempre marcaram as relações entres os povos tradicionais. Porém, conforme Lechat (2002), o conceito de Economia Solidária apareceu pela primeira vez no país em 1993, através do texto "Economia de solidariedade e organização popular" de autoria do economista chileno Luís Razeto. Nesse texto, a Economia Solidária é definida como:

Uma formulação teórica de nível científico, elaborada a partir e para dar conta de conjuntos significativos de experiências econômicas [...], que compartilham alguns traços constitutivos e essenciais de solidariedade, mutualismo, cooperação e autogestão comunitária, que definem uma racionalidade especial, diferente de outras racionalidades econômicas (RAZETO, 1999, p. 40).

Contudo, somente a partir dos anos 2000 é que o conceito vai realmente ser estruturado no país. Nessa perspectiva, Gonçalves (2010) cita a primeira edição do Fórum Social Mundial (FSM) ocorrido em 2001 em Porto Alegre (RS). Neste evento, a Economia Solidária ocupou importante espaço nas discussões, sobretudo com a articulação de entidades como a Cáritas, Movimento dos Trabalhadores Rurais Sem Terra (MST), Central Única dos Trabalhadores (CUT), lideranças 
sindicais urbanas e rurais, movimentos sociais e intelectuais, o que resultou na criação do Grupo de Trabalho Brasileiro em Economia Solidária.

Durante a segunda edição do FSM, em 2002, surgiu a ideia de se constituir um Fórum Brasileiro de Economia Solidária (FBES), o qual seria criado em junho de 2003 (FBES, 2010).

Com a eleição do presidente Luiz Inácio Lula da Silva ocorrida em outubro de 2002, as reinvindicações por políticas públicas direcionadas para a Economia Solidária se intensificam. Já em janeiro de 2003, na segunda Plenária Nacional de Economia Solidária ocorrida durante o III FSM, em Porto Alegre/RS, foi anunciada a criação da Secretaria Nacional de Economia Solidária (SENAES). Esta foi instituída a partir da Lei $\mathrm{n}^{0}$ 10.683, de 28 de maio de 2003 (GONÇALVES, 2010).

Uma das primeiras inciativas da SENAES foi a elaboração, em parceria com o FBES, do Atlas da Economia Solidária no Brasil, que deu origem, em seguida, ao Sistema Nacional de Informações da Economia Solidária (SIES). Outro importante passo se deu a partir do Decreto $\mathrm{n}^{0} 5.811$, de 21 de junho de 2006, que dispôs sobre a composição, estruturação, competência e funcionamento do Conselho Nacional de Economia Solidária (CNES).

Com a constituição da SENAES, a Economia Solidária passou a fazer parte do processo de execução orçamentária. A sua inclusão nos Planos Plurianuais (PPAs) serviu para demonstrar que o Estado brasileiro passaria a tratá-la como uma política institucional de geração de trabalho e renda. A temática foi inserida no PPA 2004-2007 através do Programa Economia Solidária em Desenvolvimento (PESD). Nos PPAs seguintes a Economia Solidária foi mantida.

A tabela 1 apresenta o orçamento para as políticas de Economia Solidária nos PPAs 20042007, 2008-2011 e 2012-2015.

Tabela 1: Orçamento da Política de Economia Solidária nos Planos Plurianuais 2004-2007; 2008-2011 e 2012-2015.

\begin{tabular}{|c|c|c|c|c|}
\hline $\begin{array}{l}\text { Plano } \\
\text { (PPA) }\end{array}$ & Plurianual & $\begin{array}{l}\text { Valor Orçado } \\
\text { (R\$) }\end{array}$ & Valor Executado (R\$) & $\begin{array}{lr}\% \text { dos } & \text { valores } \\
\text { executados } & \text { em } \\
\text { relação aos } & \text { valores } \\
\text { orçados } & \end{array}$ \\
\hline 2004-2007 & & $169.905 .966,00$ & $137.793 .738,43$ & 81,1 \\
\hline $2008-2011$ & & $208.085 .405,00$ & $85.731 .186,86$ & 41,2 \\
\hline 2012-2015 & & $577.471 .115,00$ & $131.663 .414,22$ & 22,8 \\
\hline
\end{tabular}

Fonte: https://www12.senado.leg.br/orcamento/documentos/legislacao/ldo. Acesso em: 23/03/2019.

De acordo com a tabela 1, os valores orçados nos PPAs de 2008-2011 e 2012-2015 apresentaram variações positivas em relação aos planos dos períodos anteriores. Essa variação correspondeu, respectivamente, a $22,5 \%$ e a $177,5 \%$.

Quanto aos valores executados, houve uma redução percentualmente dos valores utilizados quando comparados com os períodos anteriores. Deste modo, verifica-se que o percentual executado no PPA do quadriênio 2008-2011 $(41,2 \%)$ foi praticamente a metade do executado no período 2004$2007(81,1 \%)$. Essa diminuição nos percentuais também foi verificada no quadriênio seguinte, 20122015 , quando o percentual utilizado $(22,8 \%)$ foi menor que o executado no anterior $(41,2 \%)$. Portanto, embora os valores orçados tenham apresentado um crescimento, a execução foi a cada intervalo reduzindo os percentuais utilizados.

Para Silva (2018), além das questóes que envolvem os orçamentos, outros fatores interferiram na execução da política de Economia Solidária. Embora as dificuldades da SENAES em executar os orçamentos ocorram desde quando a Economia Solidária foi inserida no PPA, fatores de natureza econômica e política também interferiram bastante. Economicamente, cita-se a forte recessão à qual o país foi submetido a partir de 2015, como fator desestabilizador não apenas para a política de Economia Solidária, mas para todo o conjunto de políticas sociais no Brasil. Já politicamente, o processo de impeachment da então presidenta eleita Dilma Rousseff, ocorrido em 2016, teve impactos consideráveis para a política de Economia Solidária. Destaca-se a transformação da SENAES em subsecretaria, ligada ao gabinete do ministro do Trabalho, perdendo o status de secretaria que tinha desde 2003.

Esses acontecimentos impuseram uma mudança de rumo na Política Nacional de Economia Solidária que há pouco mais de uma década foi elevada para a condição de política institucional do Estado brasileiro e que dava sinais de estar se estruturando administrativamente a partir da 
constituição do SIES e do CNES. Tal mudança pode ter como resultado o esvaziamento e o consequente enfraquecimento institucional da Economia Solidária.

Diante desse cenário de incertezas, torna-se necessário que os empreendedores solidários brasileiros busquem alternativas que possibilitem o fortalecimento dos instrumentos de finanças solidárias e, consequentemente, permitam a continuidade de suas atividades e garantam a manutenção das ações desenvolvidas pela Economia Solidária.

\section{A importância social dos Fundos Rotativos Solidários}

Os FRSs, os Bancos Comunitários, os Clubes de Trocas, as Entidades de Microcrédito e as Cooperativas de Crédito são exemplos de iniciativas que constituem as Finanças da Economia Solidária. Estas procuram captar e canalizar as poupanças dos próprios interessados para a satisfação de suas necessidades de capital, visando prioritariamente à solução de problemas sociais e ambientais (SINGER, 2007).

Nesta perspectiva, Santiago (2014) destaca a exitosa iniciativa nos moldes da Economia Solidária ocorrida no Estado da Paraíba que ganhou bastante projeção, quando pequenos agricultores apoiados pelas Comunidades Eclesiais de Base (CEBs) se associaram para disponibilizar e gerir recursos financeiros visando o atendimento de necessidades imediatas da comunidade. Esse esforço deu origem em 1993 ao primeiro FRS gerido pela Articulação do Semiárido (ASA), no município de Soledade, na Paraíba.

Assim como o caso da ASA paraibana, muitas outras inciativas já existiam ou surgiram a partir do apoio de entidades que contribuíram para a consolidação das práticas solidárias. Desse modo, as pastorais sociais e as CEBs propuseram alternativas de desenvolvimento comunitário baseadas nas necessidades, práticas e culturas locais. Neste contexto, a Cáritas Brasileira começou a apoiar os Projetos Alternativos Comunitários (PACs). As ações dos PACs estavam classificadas em quatro grandes tipos, a saber: ações comunitárias, movimentos populares, ações sindicais e ação assistência-promocional. Os fundos estavam inseridos nas ações comunitárias dos projetos de caráter produtivo dado seu viés associativista (CÁRITAS BRASILEIRA, 1995).

De acordo com o NESOL-USP (2015), os fundos são classificados em dois tipos: os de Fomento e os Rotativos Solidários. Nos de Fomento, os recursos são repassados para fomentar os projetos e iniciativas de finanças solidárias e não são reembolsáveis. Já nos FRS, o recurso é captado entre os próprios participantes em uma espécie de poupança coletiva. A partir de então, passa a ser investido junto aos próprios participantes, sendo devolvido ao fundo depois de algum tempo para que possa ser novamente emprestado.

Outra classificação destacada por Barreto (2016) diferencia os fundos quanto aos recursos mobilizados, assim eles podem ser financeiros e não financeiros. Tem-se um fundo financeiro quando este disponibiliza valores monetários para as famílias que após um período devolvem em dinheiro os mesmos valores. Já o fundo não financeiro disponibiliza outro tipo de ajuda, que pode ser através do fornecimento de sementes ou animais.

Embora sejam adotadas as referidas classificações, entende-se que estas não são inflexíveis. Desse modo, muitas experiências, ainda que não apresentem todas as características para serem incluídas nas mesmas, podem ser consideradas como praticantes dessa estratégia solidária de financiamento, haja vista que apresentam elementos comuns, que são reconhecidos e valorizados pelos próprios envolvidos.

Neste artigo, adota-se a definição dos FRSs presente em Santos Filho et al. (2012), que se configuram como metodologias de apoio às atividades produtivas de caráter associativo que funcionam mediante compromisso devolutivo voluntário, com formas flexíveis de retorno monetário ou de equivalência por produtos ou serviços, dirigidos para o atendimento a empreendimentos nos territórios de ação integrada de Economia Solidária, que adotem princípios de gestão compartilhada e convivência solidária.

Compreende-se que o papel atribuído aos fundos não é apenas de prover o crédito segundo uma lógica financeira tradicional ou segundo uma lógica clientelista presente em comunidades rurais, mas, sim, de exercitar um diálogo político-pedagógico em que a comunidade se aproprie dos circuitos financeiros, apontando para a emancipação das comunidades beneficiárias a partir da lógica da solidariedade (GUSSI et al. 2012),

A fonte principal dos recursos que mantém os FRSs é oriunda das contribuições dos próprios participantes. Porém, muitos fundos recebem contribuições e financiamentos de instituições ligadas às igrejas, sindicatos, bancos, estatais e governos federal, estaduais e municipais. Nesse contexto, 
destaca-se o convênio celebrado em 2005 entre a SENAES e o Banco do Nordeste do Brasil (BNB) para o desenvolvimento do Programa de Apoio a Projetos Produtivos Solidários (PAPPS), mediante o fomento dos FRSs (NESOL-USP, 2015).

Ressalta-se que os FRSs não são baseados nos parâmetros tradicionais do sistema financeiro, os quais são pautados numa lógica meramente financista que cobra juros de uma população que vive em lugares de incipiente dinâmica socioeconômica, além de não se pautarem por princípios de racionalidade do processo de acumulação capitalista e do individualismo urbano. Portanto, os FRSs se apresentam como uma estratégia eficaz para promover a inclusão produtiva dos segmentos mais pobres e excluídos da população (FUNDAÇÃO GRUPO ESQUEL BRASIL, 2007).

A estratégia desenvolvida pelos FRSs se caracteriza por incentivar a prática da solidariedade e autogestão. Portanto, o papel exercido pelos FRSs é extremamente importante à medida que auxilia, sobretudo, famílias desprovidas de condições financeiras e que não têm acesso ao sistema bancário de financiamento. Assim, o aprimoramento das estratégias desenvolvidas pelos FRSs e a formalização de apoios e convênios junto às instituições públicas ou privadas podem abrir as portas para que ações desenvolvidas nos mais diferentes lugares do país possam ser ampliadas e o número de pessoas que praticam essa forma de Economia Solidária seja ampliado.

\section{Metodologia}

A seção apresenta os procedimentos adotados visando ao estudo do FRS da Comunidade Piqui da Rampa como indutor da Economia Solidária.

\section{Delimitação da área de estudo}

A Comunidade Quilombola Piqui da Rampa está localizada na zona rural do município maranhense de Vargem Grande. Este compõe a microrregião de Itapecuru Mirim, a qual integra a Mesorregião Norte do Maranhão.

O Piqui da Rampa é um dos povoados que compõem o Território Quilombola da Rampa (antiga Gleba da Rampa), cuja extensão compreende uma área de 6.418,02 hectares. A área deste território está distribuída entre os municípios maranhenses de Cantanhede, Pirapemas e Vargem Grande.

Além do Piqui da Rampa, outras dezessete comunidades compõem o Território Quilombola da Rampa. Ressalta-se que não existe delimitação legal entre elas, havendo somente uma divisão historicamente estabelecida e reconhecida por seus moradores a partir do espaço de uso que fazem das terras. Desse modo, o mapa 1 apresenta o espaço de uso do Piqui da Rampa, traçado de acordo com informações obtidas junto à associação comunitária em pesquisa de campo. 
Mapa 1: Espaço de uso da Comunidade Piqui da Rampa, Vargem Grande - MA.

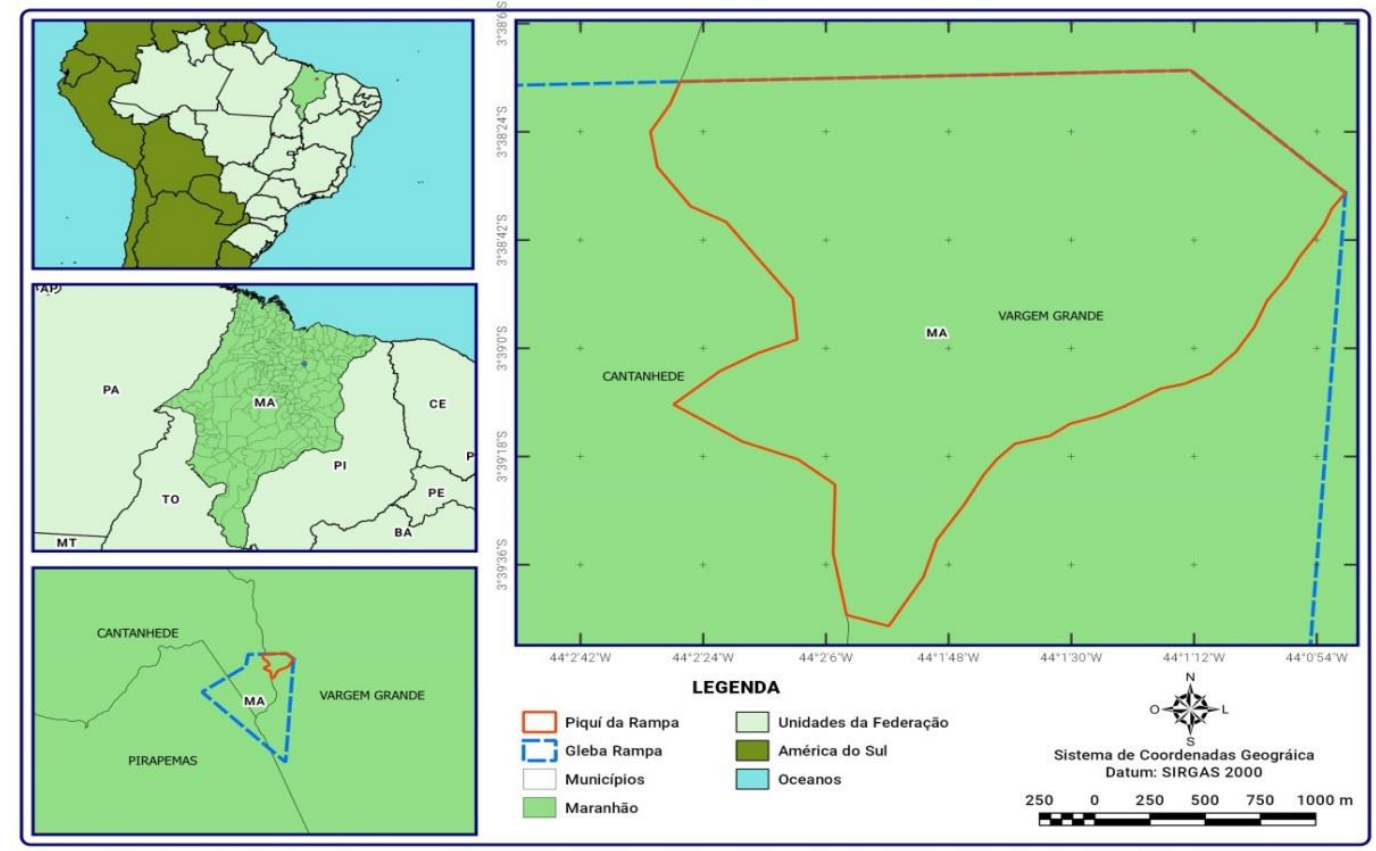

Fonte: IBGE, 2018; DATUM: SIRGAS 2000; NASCIMENTO, José Edilson do. 2018.

Vale ressaltar que os moradores que integram o Território Quilombola da Rampa, possuem a posse, mas não o título de propriedade da terra. Assim, com a finalidade de adquirirem a titulação das terras que historicamente pertenceram as suas famílias, as associações das comunidades Piqui da Rampa, São Joaquim, Rampa e Caetano passaram a requerer o título de propriedade junto ao Instituto Nacional de Colonização e Reforma Agrária (INCRA), através do processo $\mathrm{n}^{\circ}$ 54230.001872/2005-23, datado de 22 de abril de 2005. Esse processo não recebeu nenhum tipo de providência por parte do INCRA.

\section{Fontes de informações}

Esta pesquisa foi pautada em fontes primárias de informações. $\mathrm{O}$ levantamento destas foi antecedido pela realização de quatro encontros com os dirigentes da associação comunitária e demais moradores do Piqui da Rampa a partir de visitas específicas, as quais aconteceram nos dias 11 de julho de 2015, 01 de outubro de 2016, 14 de janeiro e 12 de maio de 2017. Nesses encontros foram apresentados os objetivos e a importância da pesquisa, bem como foram feitos os esclarecimentos sobre as técnicas empregadas ao longo do estudo e foi solicitada à direção da entidade representativa a autorização para a realização da pesquisa por meio da assinatura do termo de anuência. A pesquisa foi cadastrada na Plataforma Brasil a partir do CAAE (Certificado de Apresentação para Apreciação Ética) número 67240617.6.0000.5214 e Parecer 2085376.

As entrevistas (GIL, 2009; VIEIRA, 2008) e os formulários (GIL, 2009; VIEIRA, 2008) foram os instrumentos de coleta utilizados nesta pesquisa. Registra-se que as entrevistas foram aplicadas junto aos membros fundadores e dirigentes da Associação do Piqui da Rampa, Sr. E. F. (membro do Conselho Fiscal e ex-presidente) e Sr. W. S. (secretário e ex-presidente). Essas indicações foram feitas pela Associação do Piqui da Rampa e justificadas com o argumento que os indicados são grandes conhecedores da história da organização social e política da comunidade.

Já os formulários foram aplicados junto ao chefe de cada uma das trinta e duas (32) famílias da comunidade que estava na residência no momento da visita, correspondendo à totalidade do número de famílias. Ao longo da aplicação foram encontrados chefes familiares, tanto do gênero masculino quanto do gênero feminino. Os formulários foram elaborados com perguntas fechadas e padronizadas.

De posse do material coletado a partir da aplicação dos instrumentos de pesquisa, foi dado o tratamento formal às informações. Procedeu-se com a transcrição das gravações das entrevistas e análise dos conteúdos (BARDIN, 2011) contidos nas falas dos participantes. Quanto aos dados coletados por meio dos formulários, estes foram lançados e organizados através do Programa da 
Microsoft Office Excel 2010. A partir dessa ferramenta foram geradas tabelas e gráficos conforme as temáticas, a exemplo da organização associativa.

Após essas etapas, realizaram-se a análise e a interpretação das tabelas e gráficos, assim como a catalogação de referências que auxiliaram na compreensão dos dados e das falas dos sujeitos envolvidos.

\section{Do surgimento da organização associativa às ações solidárias do Fundo Rotativo Solidário da comunidade quilombola Piqui da Rampa}

A seção tem a finalidade de analisar o FRS da Comunidade Piqui da Rampa. Na primeira subseção é realizado um resgate das condições que levaram a constituição da Associação do Piqui da Rampa, assim como é feita a caracterização da organização associativa a partir de informações levantadas através dos instrumentos de pesquisa. Na subseção seguinte, trata-se da solidariedade praticada pelo FRS do Piqui da Rampa.

\section{Organização associativa da comunidade Piqui da Rampa}

A representatividade política do Piqui da Rampa é desempenhada pela Associação Comunitária e Agrícola de Trabalhadores e Trabalhadoras Remanescentes de Quilombo Piqui da Rampa. Esta associação foi constituída em 31 de julho de 2016, a partir da junção da Associação Comunitária do Povoado Piqui (criada em 1995) e da Associação de Mulheres Negras do Povoado Piqui (criada em 2001).

A origem da organização associativa da comunidade está relacionada com a atuação das CEBs da Igreja Católica. Assim, em 1984, por inciativa e orientação do pároco da Paróquia de Vargem Grande, foram iniciadas as reuniões e atividades que levaram à constituição da CEB do Piqui da Rampa.

Após mais de uma década de atuação e trabalhos desenvolvidos por meio da CEB do Piqui da Rampa, foram conseguidas importantes conquistas que marcaram a história do local enquanto comunidade e que motivou a constituição da associação comunitária.

Um empréstimo de 3.000 dólares adquirido em 1994 junto à Igreja Católica da Holanda foi o primeiro recurso financeiro conseguido pela comunidade. Essa quantia foi destinada à construção de uma casa de farinha. Como os moradores sobreviviam do trabalho realizado na roça-de-toco, resolveram no ano seguinte ao empréstimo doar meia linha de roça para contribuir com o pagamento. Desse modo, tudo que era obtido nessa meia linha de roça era destinado para o depósito da comunidade e depois comercializado e o arrecadado era destinado para uma conta bancária comunitária que os moradores passaram a chamá-la de fundo da comunidade. De acordo com o Sr. W. S., "só com as meias linhas de roça a gente conseguiu estocar mais de três mil quilos de farinha e o empréstimo que era para a gente pagar em três anos, a gente pagou em dois".

Evidencia-se dessa forma que as práticas adotadas pela comunidade convergiram para as estratégias e definições da Economia Solidária (SINGER, 2002), e do fundo rotativo (SANTOS FILHO et al., 2012), embora elas não tivessem a princípio tal intencionalidade.

Ressalta-se que a quitação do referido empréstimo antes do prazo estipulado de três anos serviu de estímulo para a comunidade buscar outros empréstimos. Nesse contexto, os moradores resolveram fundar em 15 de agosto de 1995 a "Associação Comunitária do Povoado Piqui".

O ex-presidente e membro do Conselho Fiscal da Associação do Piqui da Rampa, Sr. E. F., detalhou a motivação para a criação da referida entidade:

\footnotetext{
O que motivou a criar a Associação do Piqui da Rampa foi aquela vida que a gente teve no passado [...]. Então o que fizemos, nós fomos incentivados pela Igreja Católica, não podemos dizer que não, as Cáritas. E aí nós se juntamos e criemos, houve a necessidade de criar uma associação comunitária para tentar acessar políticas públicas. (Entrevista concedida em agosto de 2017).
}

Portanto, a criação da associação ocorreu como estratégia de enfrentamento das grandes dificuldades que assolavam a comunidade, pois a pobreza e a fome era algo marcante na vida dos moradores. Destaca-se que antes da organização associativa o trabalho era realizado de forma 
individualizada e os resultados não eram satisfatórios, uma vez que a produção não era suficiente para garantir o sustento das famílias ao longo do ano.

Com a criação da associação comunitária os moradores passaram a realizar os trabalhos coletivamente e os resultados obtidos foram mudando a realidade da comunidade. A partir dessa mudança, tornou-se comum ouvir dos moradores que "não somos ricos, continuamos pobres, mas nenhum morador passa fome como ocorria antes". Esta fala evidencia as transformações ocorridas na comunidade a partir do trabalho associativo.

O Sr. W. S. descreve a situação da comunidade antes da criação da associação comunitária e das dificuldades que tiveram para constituírem a entidade.

A pobreza era tão grande que as pessoas achavam que se já tinha chegado a comida já tinha chegado tudo. Então, assim, não acreditavam. Então na criação da associação as pessoas pensavam: Pra que? Vocês não vão conseguir nada, isso é só pra gastar dinheiro com papel [...] Então isso foi uma dificuldade grande, de inserir na cabeça das pessoas que as coisas iam dar certo, foi um desafio grande que a gente alcançou, mas com muita batalha, muita dor de cabeça, muita gente chorava, pensava em desistir, que não ia acontecer que a família ia morrer de fome porque não tinha condição, se parasse um dia para trabalhar para associação ele achava que ia morrer de fome e a gente bateu muito nessa tecla, que a gente conseguia junto vencer esse obstáculo. (Entrevista concedida em agosto de 2017).

A constituição da Associação do Piqui da Rampa e o envolvimento dos moradores são apontados pelos dirigentes comunitários como fundamentais para a consolidação da entidade representativa. Destaca-se que além do trabalho ser realizado de forma coletiva, o resultado obtido a partir da produção é dividido de forma igual entre todas as famílias envolvidas de acordo com os trabalhos realizados. Nesse sentido, o dirigente Sr. W. S., afirma que:

Hoje em dia, 95\% dos trabalhos da comunidade são comunitários e os serviços e lucros são divididos entre todas as famílias, que atualmente trabalham com o manejo orgânico e sustentável de horta comunitária, campo de sequeiro, avicultura, piscicultura entre outros. (Entrevista concedida em agosto de 2017).

Destaca-se que cabe à Associação do Piqui da Rampa a responsabilidade pela organização e pelo gerenciamento de tudo aquilo que é obtido coletivamente pelos membros da entidade. Também é função da referida associação articular junto a órgãos públicos e privados a implementação de políticas públicas que atendam à comunidade.

A Associação Comunitária do Piqui da Rampa é composta por 60 membros associados. Estes são caracterizados como agricultores e produtores familiares.

A partir da aplicação dos 32 formulários juntos aos chefes de famílias foi verificado que $69 \%$ dos chefes de famílias fazem parte da Associação do Piqui da Rampa. Os que não fazem parte da entidade representam $31 \%$ do total. Entre estes estão os que nunca tiveram interesse em participar, os que fizeram parte e se desligaram, os que alegam não terem recebido o convite e os que usam outros motivos para justificar a não participação.

Quanto à ocupação de cargos de direção da Associação do Piqui da Rampa, constatou-se entre os sócios que $54,5 \%$ já haviam ocupado ou estavam ocupando alguma função diretiva da entidade. Já o percentual daqueles que não haviam ainda exercido funções de direção correspondeu a 45,5\% do total. Embora o percentual de sócios que já exerceram ou exercem cargos de direção seja superior a 50\%, verifica-se a necessidade da inclusão de mulheres nos cargos de direção da entidade, haja vista que na atual gestão, iniciada em 31de julho de 2016 não há mulheres. Ressalta-se que a referida associação foi constituída a partir da junção de duas outras associações, incluindo a Associação de Mulheres Negras do Povoado Piqui.

Levando-se em consideração o nível de satisfação dos moradores com o trabalho desenvolvido pela associação comunitária, os entrevistados avaliaram como sendo bom (72\%) ou excelente (28\%). A satisfação manifestada é uma consequência das ações e conquistas que tiveram a associação como principal articuladora. Os projetos de eletrificação rural, de melhorias habitacionais, de melhorias das vias de acesso, da casa de farinha, do poço artesiano e da construção 
da barragem estão entre as principais conquistas, que convergem para melhoria da qualidade de vida e para o bem viver da população (GADOTTI, 2009).

Portanto, além da função desempenhada na conquista de políticas públicas, a Associação do Piqui da Rampa se destaca pelo trabalho de organização dos moradores, pela implantação do trabalho coletivo e, sobretudo, pela realização das ações solidárias desenvolvidas a partir do FRS da comunidade.

\section{Fundo Rotativo Solidário do Piqui da Rampa: a solidariedade na prática}

A organização e o trabalho coletivo praticado na Comunidade Quilombola Piqui da Rampa possibilitaram o surgimento da prática de emprestar ou doar quantias em dinheiro para as famílias da comunidade como estratégia de promover a solidariedade entre os moradores. Para tanto, passouse a recorrer ao chamado "Fundo Rotativo Solidário", também identificado como "Conta Comunitária", a qual foi criada a partir da Associação do Piqui da Rampa. A atuação solidária do fundo atende, dentro das possibilidades, tanto famílias da própria comunidade quanto de comunidades vizinhas.

No início dos anos 2000, a partir da abertura da conta comunitária da associação, configurouse na comunidade a constituição do FRS como resultado da participação dos moradores nos encontros e atividades promovidas pela Igreja Católica através das CEBs, bem como da atuação da Cáritas Brasileiras. Nesse sentido, o fundo criado na comunidade se enquadra na classificação de FRS estabelecida pelo NESOL-USP (2015).

Contudo, as ações solidárias são bem anteriores e já eram desenvolvidas no dia a dia da comunidade antes mesmo da constituição do referido fundo. Nesse sentido, o Sr. W. S., afirmou que as bases do FRS teriam sido heranças de seus antepassados e que foram sendo aprimoradas com o passar do tempo, pois os moradores sempre dividiram o pouco que tinham com os outros membros da comunidade. Desse modo, argumenta que:

O fundo rotativo, nós entendemos que ele já funcionava dentro da comunidade, porque minha mãe matava um pinto, assim da primeira pena, mas ela dividia um pedacinho com todas as famílias da comunidade, aí se pergunta até um pinto? Mas se dividia. Isso é a partilha do fundo rotativo. Assim nós ficamos nesse trabalho, na divisão, na questão se a pessoa adoecia a gente tratava da roça dele ou então se ele atrasava quando terminava a gente ajudava. (Entrevista concedida em agosto de 2017).

Essa narrativa converge para as características presentes na definição de FRS proposta por Santos Filho et al. (2012), ao valorizar as atividades produtivas de caráter associativo e que funciona a partir de compromissos voluntários, bem como ao adotar uma gestão compartilhada e uma convivência solidária.

A fonte de manutenção do FRS do Piqui da Rampa tem como origem as atividades desenvolvidas pelos próprios associados. Assim, destacam-se a festa comunitária da farinha, as diárias de trabalho e os excedentes gerados a partir da comercialização dos produtos agrícolas cultivados coletivamente.

O tradicional festejo da farinha em homenagem à Santa Luzia é realizado anualmente no segundo sábado do mês de dezembro na comunidade Piqui da Rampa. Esse festejo representa uma das principais atividades alimentadoras da Conta Comunitária. Conforme os dirigentes da Associação, cerca de $30 \%$ do que é obtido a partir dessa festa é destinado ao FRS da comunidade.

A doação de diárias de trabalho realizadas pelos associados é outro fator valorizado pelos dirigentes, pois simboliza concretamente um ato de solidariedade, à medida que se abre mão de algo em prol da coletividade. Na prática, os moradores dispensam mensalmente em favor da associação o valor correspondente a uma diária, ou seja, um dia de trabalho.

Os excedentes gerados a partir da comercialização dos produtos agrícolas resultam predominantemente da negociação realizada através do Programa de Aquisição de Alimentos (PAA) por meio de convênio estabelecido junto à Companhia Nacional de Abastecimento (CONAB). Esse convênio absorve em média $80 \%$ da produção comercializada da comunidade. $O$ restante da produção é negociado através do Programa Nacional de Alimentação Escolar (PNAE) e diretamente no mercado e feira local. 
Segundo o Sr. W. S., o FRS do Piqui da Rampa desde a sua criação recebeu somente uma única doação externa, a qual foi realizada pela Cáritas Brasileira e correspondeu ao valor de R\$ 1.200,00. Embora existam fontes de financiamento público para os FRS, a exemplo do convênio realizado entre a SENAES e o BNB, conforme anteriormente citado (NESOL-USP, 2015), registra-se que o FRS do Piqui da Rampa não recebeu, ainda, nenhum tipo de financiamento governamental.

Os recursos obtidos a partir da realização de atividades coletivas são destinados para a conta da Associação. Nessa perspectiva, a tabela 2 apresenta os valores captados por meio das atividades desenvolvidas pela comunidade no período entre os anos de 2014 a 2017.

Tabela 2: Recursos captados pela Associação do Piqui da Rampa nos anos entre 2014 a 2017.

\begin{tabular}{ll}
\hline ANO & VALOR (R\$) \\
\hline 2014 & $90.000,00$ \\
2015 & $120.000,00$ \\
2016 & $120.000,00$ \\
2017 & $130.000,00$ \\
TOTAL & $\mathbf{5 6 0 . 0 0 0 , 0 0}$ \\
\hline
\end{tabular}

Fonte: Associação Comunitária e Agrícola de Trabalhadores e Trabalhadoras Remanescentes de Quilombo Piqui da Rampa, 2018.

Levando em consideração a tabela 2, verifica-se que tem havido um crescimento na captação de recursos no decorrer dos anos. A exceção foi o ano de 2016, que manteve o mesmo valor do ano anterior. Essa informação demonstra que as atividades desenvolvidas pela comunidade Piqui da Rampa têm alcançado resultados satisfatórios.

Embora a Associação do Piqui da Rampa consiga controlar anualmente todas as entradas e saídas da Conta Comunitária, ressalta-se que não há um registro com todas as informações sistematizadas correspondentes aos valores obtidos por cada fonte alimentadora ao longo dos anos. Conforme a Fundação Grupo Esquel Brasil (2016), a inexistência de um controle eficiente das informações financeiras é uma das fragilidades na gestão dos FRSs existentes no Maranhão, pois ainda são pouco organizados e funcionam informalmente.

Para Santos Filho et al. (2012), o excesso de informalidade se constitui como grande ameaça para os FRS, o que pode inviabilizar a continuidade das exitosas experiências dessa estratégia de financiamento da Economia Solidária.

Quanto às pessoas assistidas pelo FRS do Piqui da Rampa, constatou-se que $37,5 \%$ dos participantes da pesquisa já haviam recorrido ao fundo por meio de doações ou empréstimos. Estes foram concedidos com o propósito de suprir ou minimizar necessidades consideradas emergenciais para os moradores, destacando-se as relacionadas à saúde, a funerais, à construção de moradias e a viagens.

Conforme os dirigentes da Associação do Piqui da Rampa, os valores concedidos pelo FRS podem ser tanto através de empréstimos quanto de doações. A forma de concessão é decidida coletivamente pelos associados e leva em consideração o tipo de necessidade e a situação financeira do requerente. Embora a associação tenha o registro dos valores disponibilizados, não há o controle daquilo que foi feito através de doações ou empréstimos.

Neste sentido, a tabela 3 apresenta as principais finalidades contempladas pelas doações ou empréstimos e os valores concedidos pelo FRS do Piqui da Rampa no período entre 2014 e 2017. 
Tabela 3: Empréstimos ou doações realizados pelo Fundo Rotativo Solidário do Piqui da Rampa no período de 2014 a 2017.

\begin{tabular}{|c|c|c|c|c|c|}
\hline \multirow{2}{*}{$\begin{array}{lr}\text { Finalidade do } \\
\text { empréstimo/Doação }\end{array}$} & \multicolumn{4}{|l|}{ ANO } & \multirow[b]{2}{*}{ TOTAL (R\$) } \\
\hline & $\begin{array}{l}2014 \\
(\mathrm{R} \$)\end{array}$ & $\begin{array}{l}2015 \\
(R \$)\end{array}$ & $\begin{array}{l}2016 \\
(R \$)\end{array}$ & $\begin{array}{l}2017 \\
(\mathrm{R} \$)\end{array}$ & \\
\hline Funeral & $7.000,00$ & $4.000,00$ & - & 250,00 & $11.250,00$ \\
\hline Saúde & $1.000,00$ & 700,00 & $1.300,00$ & - & $3.000,00$ \\
\hline $\begin{array}{l}\text { Construção } \\
\text { Moradia }\end{array}$ & - & 880,00 & $1.200,00$ & - & $2.080,00$ \\
\hline Viagem & - & - & - & $2.500,00$ & $2.500,00$ \\
\hline Festa comunitária & - & - & - & 600,00 & 600,00 \\
\hline $\begin{array}{l}\text { Equipamento para a } \\
\text { Igreja }\end{array}$ & - & - & - & $1.200,00$ & $1.200,00$ \\
\hline Total & $8.000,00$ & $5.580,00$ & $2.500,00$ & $4.550,00$ & $20.630,00$ \\
\hline
\end{tabular}

Fonte: Associação Comunitária e Agrícola de Trabalhadores e Trabalhadoras Remanescentes de Quilombo Piqui da Rampa. Elaborado por Nascimento, José Edilson do., 2018. Nota: Sinal convencional utilizado: - Dado numérico igual a zero não resultante de arredondamento.

Com base na tabela 3, verifica-se que 2014 foi ano em que o FRS do Piqui da Rampa disponibilizou maior valor para os empréstimos ou doações. O valor dispensado correspondeu a $9 \%$ do total arrecadado pela comunidade, $\mathrm{R} \$ 90.000,00$. Naquele ano, as despesas com auxílio funeral concentraram quase a totalidade dos valores dispensados, $87,5 \%$. No ano seguinte, a principal finalidade da concessão continuou sendo a mesma e o percentual em relação ao total concedido no ano correspondeu a $72 \%$. Utilizou-se $5 \%$ do total de $\mathrm{R} \$ 120.000,00$ com empréstimo ou doações. No ano de 2016 foi disponibilizado o menor valor, $\mathrm{R} \$ 2.500,00$ para as ações solidárias desenvolvidas pelo fundo, correspondendo a $2 \%$ do valor contido na Conta Comunitária (R\$120.000,00). Já o ano de 2017, embora não tenha sido o ano a dispensar maior valor, foi o que registrou o maior número de ocorrências (4). Naquele ano, do total de $\mathrm{R} \$ 130.000,00$ adquiridos coletivamente pela comunidade, $3,5 \%$ foi cedido solidariamente.

Considerando os participantes da pesquisa que já haviam sido beneficiados pelos empréstimos ou doações disponibilizados pelo FRS do Piqui da Rampa, registra-se que 67\% declararam não ter devolvido o valor recebido. Somente 33\% informaram ter restituído a quantia auferida. Salienta-se que a devolução informada por aqueles que dizem ter feito a restituição não ocorreu diretamente em forma de dinheiro e sim por meio de dias trabalhados em prol da associação.

Quanto aos trabalhos realizados, ressalta-se que os membros da Associação do Piqui da Rampa têm o compromisso voluntário de doar mensalmente uma diária de trabalho para a entidade. Assim, o valor correspondente à referida diária é destinado para o FRS da comunidade. Recorda-se que a definição dos fundos rotativos solidários proposta por Santos Filho et al. (2012) prevê devoluções na forma monetária ou pelo equivalente a produtos ou serviços. A forma de devolução não monetária também é encontrada na classificação dos fundos apresentada por Barreto (2016). Portanto, as diárias trabalhadas em prol da associação podem ser consideradas uma forma de devolução ao FRS da comunidade.

Os dirigentes da Associação do Piqui da Rampa defendem que as ações desenvolvidas pelo FRS da comunidade têm como objetivo principal a solidariedade. Desse modo, acreditam que o mais importante é que as pessoas tenham consciência de que os problemas estão sendo resolvidos porque teve a participação e a ajuda de toda a comunidade. Tais práticas apontam para emancipação da Comunidade a partir da lógica da solidariedade (GUSSI et al. 2012).

Dessa forma, entende-se que o FRS do Piqui da Rampa está de acordo com a Economia Solidária à medida que coloca em prática os seus princípios, ou seja, a autogestão, a solidariedade, a reciprocidade e o trabalho coletivo.

\section{Considerações finais}

O surgimento da organização associativa da comunidade quilombola Piqui da Rampa é considerado como o acontecimento que transformou a história da comunidade, pois com a criação da entidade as ações desenvolvidas, o planejamento, as decisões e as atividades produtivas e comerciais passaram a ser realizadas coletivamente. 
O trabalho realizado pela Associação do Piqui da Rampa é uma consequência direta da organização e, sobretudo, da união dos moradores. Nesse contexto, destaca-se que o FRS foi constituído como estratégia de promover a solidariedade na comunidade a partir da concessão de doações ou empréstimos para as pessoas minimizarem as suas necessidades.

Embora o FRS do Piqui da Rampa apresente características que convergem para definições e classificações existentes, entende-se que este precisa avançar em relação à formalização, assim como na organização administrativa, no registro e no controle das atividades.

Portanto, a função desempenhada pelo FRS do Piqui da Rampa ultrapassa a simples questão da doação. A sua importância está relacionada com os valores e princípios que são construídos ou realçados como a solidariedade e a reciprocidade.

\section{Referências}

BARDIN, Laurence. Análise de conteúdo. Tradução de Luís Antero Reto e Augusto Pinheiro. São Paulo: Edições 70, 2011.

BARRETO, Simaia S. Os fundos rotativos solidários no Brasil: uma perspectiva a partir do mapeamento dos fundos de 2011-2012. Boletim do Mercado de Trabalho: conjuntura e análise, Brasília: Ipea: MTPS, v. 1, n. 60, p. 101-108, 2016. Disponível em: http://repositorio.ipea.gov.br/bitstream/11058/6627/1/bmt60_fundos.pdf. Acesso em: 22 jan. 2019.

CÁRITAS BRASILEIRA. Sobrevivência e cidadania: Avaliação qualitativa dos projetos alternativos da Cáritas Brasileira. Brasília: Editora Universidade de Brasília, 1995.

FÓRUM BRASILEIRO DE ECONOMIA SOLIDÁRIA (FBES). Economia Solidária: outra economia a serviço da vida acontece. 2010. Disponível em: http://www.numiecosol.ufscar.br/documentos/textos-economia-solidaria/cartilha-economiasolidaria-outra-economia-a-servico-da-vida-acontece/view. Acesso em: 16 maio 2018.

FUNDAÇÃO GRUPO ESQUEL BRASIL (org.). Fundos Solidários: por uma política de emancipação produtiva dos movimentos sociais. Mobilização em prol de uma política pública de apoio a Fundos Solidários. Caderno 1. Fortaleza: Fundação Grupo Esquel Brasil/BNB, 2007. Disponível em: http://caritas.org.br/wp-content/uploads/2011/03/Caderno-1-FUNDOS-SOLID\%C3\%81RIOS-PORUMA-POL\%C3\%8DTICA-DE-EMENCIPA\%C3\%87\%C3\%830-PRODUTIVA-DOS-MOVIEMNTOSSOCIAIS.pdf. Acesso em: 24 abr. 2018.

FUNDAÇÃO GRUPO ESQUEL BRASIL. Fundos Solidários: tecendo redes, entrelaçando vida. Maranhão, 2016.

GADOTTI, Moacir. Economia solidária como práxis pedagógica. São Paulo: Editora e Livraria Instituto Paulo Freire, 2009.

GIL, Antonio Carlos. Como elaborar projetos de pesquisa. 4. ed. São Paulo: Atlas, 2009.

GONÇALVES, Alicia F. A história dos fundos rotativos solidários no estado da Paraíba: a construção político-institucional de uma política pública. Revista Gestão Pública: Práticas e Desafios. Recife, v. I, n. 1, p. 225-241, fev. 2010. Disponível em: https://periodicos.ufpe.br/revistas/gestaopublica/article/viewFile/1118/861. Acesso em: 24 abr. 2018.

GUSSI, A.; SANTOS FILHO, C. dos; ALMEIDA, G. F. B. de. A experiência de fomento público a Fundos Rotativos Solidários no Nordeste: o caso da Rede Bodega. Mercado de trabalho: conjuntura e análise. Brasília: Ipea: MTE, n. 60, p. 77-86, 2012. Disponível em: http://repositorio.ipea.gov.br/bitstream/11058/3907/1/bmt50_econ03_aexperiencia.pdf. Acesso em: 25 nov. 2018. 
LECHAT, Noëlle M. P. Economia social, economia solidária, terceiro setor: do que se trata? Civitas - Rev. de Ciências Sociais, Porto Alegre, Ano 2, n. 1, p. 123-140, junho 2002. Disponível em: http://revistaseletronicas.pucrs.br/ojs/index.php/civitas/article/view/91. Acesso em: 04 abr. 2018.

NÚCLEO DE ECONOMIA SOLIDÁRIA - NESOL-USP. Finanças Solidárias (Cadernos de Finanças Solidárias). São Paulo - NESOL-USP, 2015. Disponível em: http://centrodeestudoseassessoria.org.br/wp-content/uploads/2017/08/Cadernos-Finan\%C3\%A7asSolidarias-NESOL_USP.pdf. Acesso em: 24 abr. 2018.

RAZETO, L. Economia de solidariedade e organização popular. In: GADOTTI, M.; GUTIERREZ F. (org.). Educação comunitária e economia popular. São Paulo: Cortez, 1999.

SANTIAGO, E. G. Movimentos Sociais da Economia Solidária na América Latina: Simbolismos de uma Luta Contra o Capitalismo Hegemônico. In: CARVALHO, Alba Maria Pinho de; HOLANDA, Francisco Uribam Xavier de (org.). Brasil e América Latina: percursos e dilemas de uma integração. Fortaleza: Edições UFC, 2014. Disponível em: http://www.repositorio.ufc.br/bitstream/riufc/21286/3/2014_capliv_egsantiago.pdf. Acesso em: 26 abr. 2018.

SANTOS FILHO, C. dos; MARQUES, R.; PAIVA, V. R. A. de; PEREIRA, W. A. Fundo Rotativo Solidário do Fórum da Economia do Negro: Uma Experiência de Finanças Solidárias com Recorte Racial em Fortaleza, Ceará. Cadernos Gestão Social, Salvador, v. 3, n. 2, p. 184-204, jul./dez. 2012. Disponível em: http://www.periodicos.adm.ufba.br/index.php/cgs/article/viewArticle/291. Acesso em: 14 maio 2018.

SILVA, Sandro P. A política de Economia Solidária no ciclo orçamentário nacional (2004-2018): inserção, expansão e crise de paradigma (Texto para discussão). Brasília: Rio de Janeiro: Ipea, 2018. Disponível em: http://www.ipea.gov.br/portal/index.php?option=com content\&view $=$ article\&id $=34427 \&$ Itemid $=4$ 33. Acesso em: 22 mar. 2019.

SINGER, Paul. Introdução à Economia Solidária. São Paulo: Editora Fundação Perseu Abramo, 2002.

SINGER, Paul. Economia Solidária. In: CATTANI, Antônio David (org.). A Outra Economia. Porto Alegre: Veraz Editores, 2003.

SINGER, Paul. Por um sistema financeiro social. Folha de São Paulo, São Paulo, 10 jul. 2007. Disponível em: https://acervo.folha.com.br//leitor.do?anchor $=5226026 \& \mathrm{pd}=506 \mathrm{aa} 72 \mathrm{~cd} 1 \mathrm{dca} 266 \mathrm{fb} 6 \mathrm{c} 3203175 \mathrm{bcc} 49$. Acesso em: 25 mar. 2019.

VIEIRA, Sonia. Como escrever uma tese. 6. ed. São Paulo: Atlas, 2008.

WELLEN, Henrique André Ramos. Contribuição à crítica da 'economia solidária'. Revista Katálysis. Florianópolis v. 11, n. 1, p. 105-115, jan./jun. 2008. Disponível em: http://www.scielo.br/pdf/rk/v11n1/10.pdf. Acesso em: 13 out. 2018. 